\title{
Eating occasions and the contribution of foods to sodium and potassium intakes in adults
}

\author{
Kacie M Dickinson*, Lily Chan, Carly J Moores, Jacqueline Miller, Jolene Thomas, \\ Alison Yaxley, Kathryn Jackson, Kaye Mehta, Louisa Matwiejczyk, Amanda Wray and \\ Michelle Miller \\ Nutrition and Dietetics, College of Nursing and Health Sciences, Flinders University, GPO Box 2100, Adelaide, \\ SA 5001, Australia
}

Submitted 23 May 2017: Final revision received 24 August 2017: Accepted 4 September 2017: First published online 7 November 2017

\begin{abstract}
Objective: To examine dietary $\mathrm{Na}$ and $\mathrm{K}$ intake at eating occasions in Australian adults and identify the contribution of major food sources to $\mathrm{Na}$ and $\mathrm{K}$ at different eating occasions.

Design: Secondary analysis of $24 \mathrm{~h}$ recall diet data from the Australian Health Survey (2011-2013).

Setting: Nationally representative survey in Australia.

Subjects: Male and female Australians aged $18-84$ years ( $n$ 7818).

Results: Dinner contributed the greatest proportion to total daily Na intake (33\%) and $\mathrm{K}$ intake (35\%). Na density was highest at lunch $(380 \mathrm{mg} / \mathrm{MJ})$ and $\mathrm{K}$ density highest at between-meal time eating occasions ( $401 \mathrm{mg} / \mathrm{MJ})$. Between-meal time eating occasions provided $20 \%$ of daily $\mathrm{Na}$ intake and $26 \%$ of daily $\mathrm{K}$ intake. The major food group sources of $\mathrm{Na}$ were different at meal times (breads and mixed dishes) compared with between-meal times (cakes, muffins, scones, cake-type desserts). The top food group sources of $\mathrm{K}$ at meal times were potatoes and unprocessed meat products and dishes.

Conclusions: Foods which contributed to $\mathrm{Na}$ and $\mathrm{K}$ intake differed according to eating occasion. Major food sources of $\mathrm{Na}$ were bread and processed foods. Major food sources of $\mathrm{K}$ were potatoes and meat products and dishes. Public health messages that emphasise meal-based advice and diet patterns high in vegetables, fruits and unprocessed foods may also aid reduction in dietary $\mathrm{Na}$ intake and increase in dietary $\mathrm{K}$ intake.
\end{abstract}

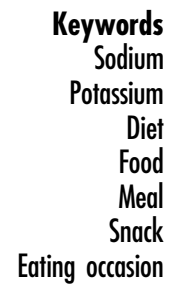

High $\mathrm{Na}$ intake is a major risk factor for high blood pressure and $\mathrm{CVD}^{(1,2)}$. It is estimated that 2.5 million deaths could be prevented each year worldwide if salt consumption were reduced by $6 \mathrm{~g} / \mathrm{d}^{(3)}$. Low dietary $\mathrm{K}$ intake also contributes to an increase in blood pressure and CVD and stroke ${ }^{(1)}$. Intervention studies increasing intake of dietary $\mathrm{K}$ or fruit and vegetables (major $\mathrm{K}$ food sources) have demonstrated blood pressure-lowering effects in normotensive and hypertensive participants ${ }^{(4,5)}$. Previous studies have also indicated that the ratio of $\mathrm{Na}$ to $\mathrm{K}$ is a more important risk factor for hypertension and CVD than dietary $\mathrm{Na}$ or $\mathrm{K}$ intake alone ${ }^{(6-8)}$.

$\mathrm{Na}$ intake of Australian adults estimated by urinary $\mathrm{Na}$ excretion is consistently reported to be in excess of the suggested dietary target (SDT) of $86 \mathrm{mmol} / \mathrm{d}$ for reducing chronic disease $^{(9)}$. Recent national estimates of $\mathrm{Na}$ intake from food sources alone indicate $71 \%$ of males and $32 \%$ of females aged $>19$ years exceeded the previous upper limit of consumption for $\mathrm{Na}(2300 \mathrm{mg} / \mathrm{d})$. In addition, $64 \%$ of adults in Australia report adding salt to foods during cooking or at the table ${ }^{(10)}$. Therefore, total $\mathrm{Na}$ intake is likely to be higher than these figures as they do not include this discretionary $\mathrm{Na}$ added to foods during preparation, cooking and at the table ${ }^{(10)}$. The most recent estimate of salt intake in Australia is $9 \cdot 0-9 \cdot 9 \mathrm{~g} / \mathrm{d}$, which takes account of $\mathrm{Na}$ from foods, processing and discretionary salt added to foods ${ }^{(11)}$.

Few studies have reported $\mathrm{K}$ intake of Australian adults. The adequate intake (AI) for $\mathrm{K}$ is $97 \mathrm{mmol} / \mathrm{d}(3800 \mathrm{mg} / \mathrm{d})$ for men and $72 \mathrm{mmol} / \mathrm{d}(2800 \mathrm{mg} / \mathrm{d})$ for women. The SDT for $\mathrm{K}$ is $120 \mathrm{mmol} / \mathrm{d}(4700 \mathrm{mg} / \mathrm{d})$, which is recommended to reduce risk of high blood pressure and $\mathrm{CVD}^{(9)}$. Findings of the few published studies show K intake to be 80-90\% of the $\operatorname{SDT}^{(12)}$.

Identifying foods that contribute high proportions of $\mathrm{Na}$ to the diet of Australians is an important step towards reducing $\mathrm{Na}$ intakes and can aid meal-based approaches to complement food-based dietary recommendations. 
Currently there are only a few studies that document major food sources contributing to $\mathrm{Na}$ intake of Australian adults. Among these, bread and cereals have been found to contribute the greatest proportion of total daily $\mathrm{Na}$ intake ${ }^{(13-15)}$; however, these studies are limited by small or convenience samples of adults. Fewer studies have reported food sources of $\mathrm{K}$ in Australian adults. Margerison et $a l^{(12)}$ recently reported vegetable products/dishes, breads and cereals and meat products/dishes as major contributors to $\mathrm{K}$ intake in a sample of older Australian adults. Identifying major food sources of $\mathrm{Na}$ and $\mathrm{K}$ is important for cardiovascular health as it could provide targets to inform policy and complement the food-based recommendations of the Australian Dietary Guidelines for adults by providing meal-based diet recommendations ${ }^{(16)}$.

Recent interest in dietary and meal pattern research has emerged as a potentially useful way to better understand the ways in which foods are consumed in real life and can aid interpretation of food-based dietary guidelines and assist populations in achieving dietary targets (such as the Australian Guide to Healthy Eating) ${ }^{(16)}$. Meal and snack patterns may affect the development of several chronic diseases $^{(17,18)}$ with a potential mechanism being impaired vascular function following exposure to individual meals with high $\mathrm{Na}$ and low $\mathrm{K}$ content ${ }^{(19-22)}$. There are few previous studies that have reported the food sources and distribution of $\mathrm{Na}$ and $\mathrm{K}$ consumption across meal time and between-meal time occasions. Young people are reported to consume more $\mathrm{Na}$ from snack foods compared with meals ${ }^{(23,24)}$. Margerison et al. reported that the lunch meal contributes the greatest proportion of $\mathrm{Na}$ intake among older adults (34\% of daily Na intake) ${ }^{(12)}$. No other previous studies have reported $\mathrm{Na}$ and $\mathrm{K}$ intakes and food sources at different eating occasions.

Therefore, to address this gap, we conducted a secondary data analysis of the National Nutrition and Physical Activity Survey (NNPAS) 2011-12 component of the Australian Health Survey (AHS) 2011-13 $3^{(10)}$ to examine dietary Na and $\mathrm{K}$ intakes at meal times in Australian adults and identify the contribution of major food sources to $\mathrm{Na}$ and $\mathrm{K}$ at different eating occasions.

\section{Methods}

\section{Study population}

The present study is a secondary analysis of the AHS 2011-13 ${ }^{(10)}$, which is the largest and most comprehensive health survey conducted in Australia. The data used in the present study were collected during the NNPAS 2011-12, one of four components of the AHS 2011-13, and provided information relating to dietary intakes (via two $24 \mathrm{~h}$ dietary recalls at least $8 \mathrm{~d}$ apart, using computer-assisted interview instruments). Details of the survey methods have been published by the Australian Bureau of Statistics in the Australian Health Survey Users' Guide 2011-13 ${ }^{(25)}$.
Permission was obtained from the Australian Bureau of Statistics to access the basic confidentialised unit record file, released on 13 November 2014, to enable data analysis. Males and females aged 18-84 years for whom measured height, weight and age were reported ( $n$ 7818) were included in the analysis.

Data from the first $24 \mathrm{~h}$ dietary recall conducted at the face-to-face interview were used to estimate nutrient and food intakes in the present analysis. The $24 \mathrm{~h}$ dietary recall was conducted by trained interviewers using a computerassisted interview system, the Automated Multiple-Pass Method $^{(26)}$, to ensure consistent and complete data collection. One day of data can be used as an estimate of the mean of the usual intake distribution in the population, whereas the usual intake of an individual would have required more than one day.

\section{Eating occasions and food classification}

The AUSNUT 2011-13 database contains fifty-one nutrient values for all foods and beverages reported in the $24 \mathrm{~h}$ dietary recalls in the NNPAS ${ }^{(27)}$. The AUSNUT database was specifically developed for use with the AHS. A key consideration is that the Na content of some home-prepared foods may be underestimated. This is because salt added during cooking has not been accounted for in recipes used in the database ${ }^{(28)}$. Therefore the estimates of daily $\mathrm{Na}$ intake presented here are likely underestimated and differ from the values of total daily $\mathrm{Na}$ intake that have been estimated drawing on a combination $24 \mathrm{~h}$ urinary $\mathrm{Na}$ excretion and $24 \mathrm{~h}$ recall data ${ }^{(11)}$.

The NNPAS 2011-12 identified thirteen separate eating occasions for the consumption of foods and beverages. Eating occasions were classified as 'meal time', which comprises the three typical daily meals of breakfast (includes breakfast and brunch), lunch and dinner, and 'between-meal time' (includes supper, morning tea, afternoon tea, snack, beverage/drink, extended consumption and other). Foods and beverages that were consumed on an occasion not determined were not classified as either meal time or between-meal time foods and beverages, and hence are excluded from eating occasion analyses (101 of 212235 food/ beverage items consumed). However, the nutrients from these foods and beverages have been included in estimations of daily $\mathrm{Na}, \mathrm{K}$ and energy intakes. The proportion of $\mathrm{Na}$ intake from foods and beverages in the present study is reported at the 3-digit code (sub-major food group) level.

To standardise intakes for comparisons, $\mathrm{Na}$ and $\mathrm{K}$ densities, defined as mg/MJ energy intake, were calculated.

\section{Statistical analysis}

The statistical software package Stata version 10 was used in the data analysis. Since NNPAS 2011-12 was conducted using a stratified multistage area sampling of private dwellings, sampling weights were applied when producing estimates to compensate for unequal probability of selection of the sampled person, non-response, and non-coverage. 
Variance and test statistics were estimated by the replicate weights technique and included the use of sixty replicate weights provided in the data set. These replicate weights were generated by the Australian Bureau of Statistics under the delete-one-group jack-knife method. Descriptive statistics are presented as means with their standard errors. ANOVA was used to test the difference between groups and a $P$ value of $<0.05$ was set to establish statistical significance. Percentage of $\mathrm{Na}$ from each food group was calculated as: (sum of $\mathrm{Na}$ from food group (mg)/total sum of $\mathrm{Na}$ from all foods $(\mathrm{mg})) \times 100^{(29)}$. Ratio of $\mathrm{Na}$ to $\mathrm{K}$ was calculated as:

$$
\mathrm{Na}: \mathrm{K}=\frac{\mathrm{Na} \text { intake }(\mathrm{mg}) / 23}{\mathrm{~K} \text { intake }(\mathrm{mg}) / 39},
$$

where $1 \mathrm{mmol} \mathrm{Na}=23 \mathrm{mg} \mathrm{Na}$ and $1 \mathrm{mmol} \mathrm{K}=39 \mathrm{mg} \mathrm{K}$.

Estimates include $\mathrm{Na}$ naturally present in foods as well as $\mathrm{Na}$ added during processing, but exclude the 'discretionary salt' added by consumers in home-prepared foods or 'at the table'. Na from supplements and medications is also excluded.

\section{Results}

Demographic characteristics of this nationally representative sample of Australian adults aged 18-84 years, according to quintile of $\mathrm{Na}$ intake, are illustrated in Table 1.
Males consumed more $\mathrm{Na}, \mathrm{K}$ and energy than females. Higher $\mathrm{Na}$ and $\mathrm{K}$ intakes were associated with younger age (both genders), and with higher body weight (females only). Mean $\mathrm{Na}$ density was not significantly different between males and females (males 285.0 (SE 2.4) mg/MJ $v$. females 290.5 (se 3.0) mg/MJ; $P=0 \cdot 174$ ). Mean $\mathrm{K}$ density was lower among males (333.4 (sE 2.4) mg/MJ) compared with females $(363.1$ (se 2.6) mg/MJ; $P<0.001$ ). Na:K was higher among males than females (males 1.65 (SE 0.02) $v$. females 1.54 (se 0.02); $P=0.002$ ) and was significantly different across quintiles of $\mathrm{Na}$ intake $(P<0 \cdot 001)$. Na density and $\mathrm{Na}: \mathrm{K}$ were lower, and $\mathrm{K}$ density higher, in older adults compared with younger adults $(P<0 \cdot 005)$.

\section{Sodium and potassium at meal and between-meal eating occasions}

Overall, main meals contributed $81 \%$ of mean daily $\mathrm{Na}$ intake among all adults. The eating occasion contributing the greatest amount of $\mathrm{Na}$ on the day of the survey was dinner $33 \%$ of total daily $\mathrm{Na}$ intake), followed by lunch (31\%), snacks (19\%) and breakfast (16\%; Fig. 1). There were no statistically significant gender differences in percentage of daily $\mathrm{Na}$ intake at any eating occasion (Fig. 2). There was a significant trend observed across age groups for proportions of $\mathrm{Na}$ intake from meal times compared with snacks (Table 2) that indicates younger adults consume a greater proportion of total $\mathrm{Na}$ from foods consumed between meals than older adults.

Table 1 Baseline characteristics by quintile of sodium intake and gender among a nationally representative sample of Australian adults aged 18-84 years with known height and weight $(n 7818)$, Australian Health Survey (2011-13)

\begin{tabular}{|c|c|c|c|c|c|c|c|c|c|c|c|}
\hline & \multicolumn{10}{|c|}{ Quintile } & \multirow[b]{3}{*}{$P$ value } \\
\hline & \multicolumn{2}{|c|}{1} & \multicolumn{2}{|c|}{2} & \multicolumn{2}{|c|}{3} & \multicolumn{2}{|l|}{4} & \multicolumn{2}{|l|}{5} & \\
\hline & Mean & SE & Mean & SE & Mean & SE & Mean & SE & Mean & SE & \\
\hline \multicolumn{12}{|l|}{ Women } \\
\hline Number in each quintile $(n)$ & \multicolumn{2}{|c|}{839} & \multicolumn{2}{|c|}{817} & \multicolumn{2}{|c|}{850} & \multicolumn{2}{|c|}{810} & \multicolumn{2}{|c|}{770} & \\
\hline $\mathrm{Na}$ intake (mg) & $859 \cdot 4$ & $12 \cdot 7$ & $1408 \cdot 8$ & 5.4 & $1904 \cdot 5$ & $7 \cdot 2$ & 2546.9 & $10 \cdot 9$ & $3940 \cdot 2$ & $41 \cdot 8$ & 0.001 \\
\hline $\mathrm{K}$ intake (mg) & $2181 \cdot 8$ & 59.5 & $2479 \cdot 8$ & $54 \cdot 1$ & $2598 \cdot 4$ & $52 \cdot 1$ & $2786 \cdot 9$ & $47 \cdot 0$ & $3190 \cdot 5$ & $52 \cdot 2$ & 0.001 \\
\hline Energy intake (MJ) & $5424 \cdot 7$ & $119 \cdot 4$ & $6489 \cdot 4$ & $103 \cdot 8$ & 7346.9 & $108 \cdot 5$ & 8444.6 & $112 \cdot 6$ & $10104 \cdot 2$ & $129 \cdot 5$ & 0.001 \\
\hline Daily $\mathrm{Na}$ density (mg/MJ) & 183.5 & $4 \cdot 9$ & 244.5 & $4 \cdot 4$ & $285 \cdot 0$ & $4 \cdot 7$ & $325 \cdot 3$ & $4 \cdot 3$ & $414 \cdot 2$ & $6 \cdot 2$ & 0.001 \\
\hline Daily $\mathrm{K}$ density (mg/MJ) & $412 \cdot 0$ & $6 \cdot 1$ & $387 \cdot 0$ & $5 \cdot 8$ & $358 \cdot 4$ & $5 \cdot 2$ & $335 \cdot 2$ & $4 \cdot 2$ & $322 \cdot 8$ & 5.4 & 0.001 \\
\hline Daily Na:K & 0.86 & 0.03 & $1 \cdot 19$ & 0.03 & 1.48 & 0.03 & $1 \cdot 78$ & 0.03 & $2 \cdot 41$ & 0.05 & 0.001 \\
\hline Age (years) & $47 \cdot 9$ & 0.8 & $47 \cdot 1$ & 0.7 & $46 \cdot 2$ & 0.7 & $45 \cdot 0$ & 0.7 & $40 \cdot 3$ & 0.8 & 0.001 \\
\hline Weight (kg) & $69 \cdot 4$ & 0.6 & $70 \cdot 2$ & 0.7 & $70 \cdot 9$ & 0.8 & $73 \cdot 0$ & 0.8 & $71 \cdot 2$ & 0.8 & 0.005 \\
\hline Height (cm) & $161 \cdot 1$ & 0.3 & 161.9 & 0.4 & $162 \cdot 0$ & 0.4 & $162 \cdot 7$ & 0.3 & 163.9 & 0.4 & 0.001 \\
\hline BMI $\left(\mathrm{kg} / \mathrm{m}^{2}\right)$ & $26 \cdot 7$ & 0.2 & $26 \cdot 8$ & 0.3 & $27 \cdot 0$ & 0.3 & $27 \cdot 6$ & 0.3 & $26 \cdot 5$ & 0.3 & 0.689 \\
\hline \multicolumn{12}{|l|}{ Men } \\
\hline Number in each quintile $(n)$ & \multicolumn{2}{|c|}{775} & \multicolumn{2}{|c|}{778} & \multicolumn{2}{|c|}{743} & \multicolumn{2}{|c|}{712} & \multicolumn{2}{|c|}{724} & \\
\hline Na intake (mg) & $1095 \cdot 8$ & $14 \cdot 6$ & $1872 \cdot 4$ & $10 \cdot 9$ & 2544.9 & $9 \cdot 3$ & $3383 \cdot 4$ & $12 \cdot 3$ & $5157 \cdot 5$ & $71 \cdot 8$ & 0.001 \\
\hline $\mathrm{K}$ intake (mg) & $2710 \cdot 2$ & $56 \cdot 0$ & $3000 \cdot 4$ & 73.5 & $3209 \cdot 1$ & $72 \cdot 2$ & 3449.9 & $51 \cdot 7$ & 3902.4 & 83.5 & 0.001 \\
\hline Energy intake (MJ) & $7215 \cdot 4$ & $124 \cdot 8$ & $8802 \cdot 8$ & $177 \cdot 2$ & $9839 \cdot 4$ & $159 \cdot 1$ & $11137 \cdot 8$ & $141 \cdot 3$ & 13475.4 & $201 \cdot 3$ & 0.001 \\
\hline Daily Na density (mg/MJ) & $170 \cdot 2$ & 3.7 & $236 \cdot 8$ & 4.5 & 283.7 & 3.9 & $326 \cdot 9$ & 4.6 & $407 \cdot 0$ & 6.4 & 0.001 \\
\hline Daily K density (mg/MJ) & $384 \cdot 1$ & $6 \cdot 0$ & $344 \cdot 8$ & $5 \cdot 6$ & $327 \cdot 4$ & 4.5 & 313.9 & $4 \cdot 4$ & $296 \cdot 8$ & $5 \cdot 4$ & 0.001 \\
\hline Daily Na:K & 0.89 & 0.05 & $1 \cdot 30$ & 0.04 & 1.64 & 0.04 & 1.91 & 0.04 & 2.52 & 0.06 & 0.001 \\
\hline Age (years) & 48.5 & 0.7 & $47 \cdot 1$ & 0.7 & $44 \cdot 4$ & 0.8 & $42 \cdot 8$ & 0.8 & 38.9 & 0.6 & 0.001 \\
\hline Weight (kg) & $84 \cdot 2$ & 0.8 & $85 \cdot 1$ & 0.8 & $85 \cdot 2$ & 0.8 & $86 \cdot 4$ & 0.9 & 85.7 & 0.9 & 0.164 \\
\hline Height (cm) & $174 \cdot 2$ & 0.4 & $175 \cdot 1$ & 0.4 & $176 \cdot 2$ & 0.4 & $177 \cdot 1$ & 0.3 & $177 \cdot 0$ & 0.5 & 0.001 \\
\hline BMI $\left(\mathrm{kg} / \mathrm{m}^{2}\right)$ & $27 \cdot 6$ & 0.2 & $27 \cdot 7$ & 0.2 & $27 \cdot 4$ & 0.2 & $27 \cdot 6$ & 0.3 & $27 \cdot 3$ & 0.2 & 0.321 \\
\hline
\end{tabular}

SE estimated by the delete-one-group jack-knife replicate weights method. 
Main meals contributed $74 \%$ of mean daily $\mathrm{K}$ intake among all adults (Fig. 1). The greatest contribution to $\mathrm{K}$ on the day of the survey was dinner $(35 \%$ of total daily $\mathrm{K}$

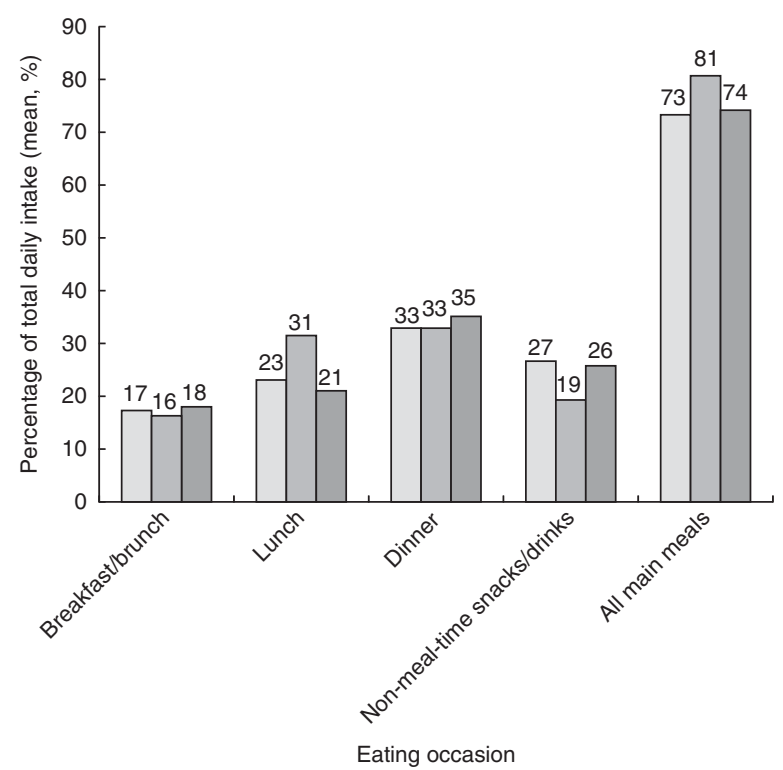

Fig. 1 Contribution to total daily energy (including dietary fibre; $\square$ ), sodium ( $\square$ ) and potassium ( $\square$ ) intakes from meals/ snacks among a nationally representative sample of Australian adults aged 18-84 years with known height and weight ( $n$ 7818), Australian Health Survey (2011-13)

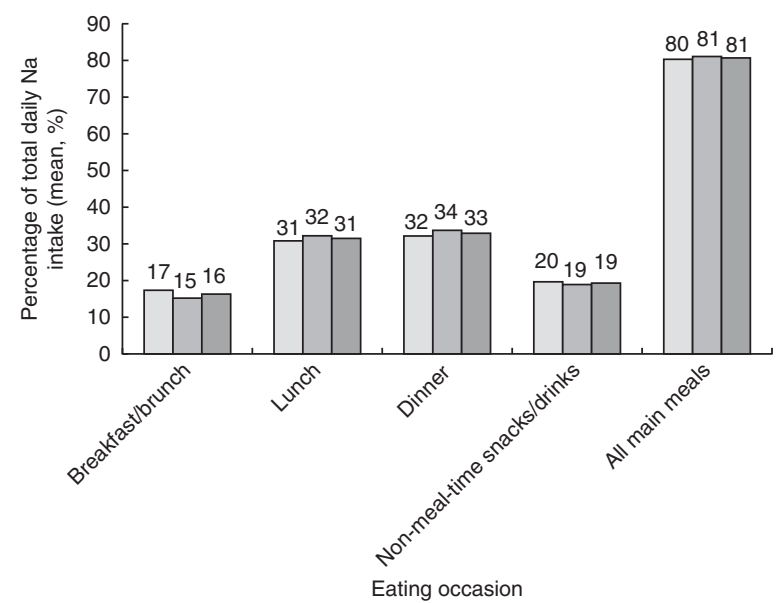

Fig. 2 Contribution to total sodium intake from meals/snacks, overall ( $\square$ ) and according to gender ( $\square$, males; $\square$, females), among a nationally representative sample of Australian adults aged 18-84 years with known height and weight ( $n$ 7818), Australian Health Survey (2011-13) intake), followed by snacks (26\%), lunch (21\%) and breakfast (18\%).

The $\mathrm{Na}$ and $\mathrm{K}$ densities at each eating occasion are presented in Fig. 3. Total mean density was $288 \mathrm{mg} / \mathrm{MJ}$ per $\mathrm{d}$ for $\mathrm{Na}$ and $348 \mathrm{mg} / \mathrm{MJ}$ per $\mathrm{d}$ for $\mathrm{K}$ (Fig. 3). The greatest $\mathrm{Na}$ density at meal occasions was lunch $(379 \mathrm{mg} / \mathrm{MJ})$, followed by dinner (306 mg/MJ), breakfast (231 mg/MJ) and snacks (200 mg/MJ). K density was greatest for snacks $(396 \mathrm{mg} / \mathrm{MJ})$, followed by dinner $(377 \mathrm{mg} / \mathrm{MJ})$, breakfast (355 mg/MJ) and lunch (299 mg/MJ).

\section{Top food group sources of sodium and potassium}

The food group mixed dishes where cereal is the major ingredient contributed the greatest proportion of total daily $\mathrm{Na}$ intake (14.6\%) with savoury pasta/noodle and sauce dishes contributing most (22.4\%) followed by burgers (19.0\%), pizza $(16 \cdot 1 \%)$, sandwiches and filled rolls (15.3\%). Potatoes contributed the greatest proportion of total daily $\mathrm{K}$ intake (221.6 mg; $7.5 \%$ ).

\section{Top food group sources of sodium and potassium at meal and between-meal eating occasions}

The top sources of $\mathrm{Na}$ differed at each of the specified eating occasions, as summarised in the online supplementary material, Supplemental Table 1 . Breads and cereals contributed most $\mathrm{Na}$ at lunch $(17 \cdot 3 \%)$, mixed dishes where cereal is the major ingredient at dinner (21.4\%) and cakes, muffins, scones, cake-type desserts (9.8\%) at snack times.

Major contributors to $\mathrm{Na}$ intake at breakfast were regular breads and bread rolls (24.0\%), breakfast cereals (11.0\%) and processed meat (10.7\%). At lunch, the major contributors were regular breads and bread rolls (17.3\%), mixed dishes where cereal is the major ingredient $17 \cdot 1 \%$ ), processed meat (8.1\%), cheese (5.1\%), pastries (4.9\%), and gravies and savoury sauces (4.4\%). Mixed dishes where cereal is the major ingredient also contributed the greatest proportion of $\mathrm{Na}$ at dinner $(21.4 \%)$, followed by gravies and savoury sauces $(8.3 \%)$, mixed dishes where poultry or feathered game is the major component $(6 \cdot 6-5 \cdot 7 \%)$, sausages/frankfurts and saveloys (5.3\%), regular breads and rolls $(5 \cdot 3 \%)$, and soup $(5 \cdot 1 \%)$.

At the defined between-meal time occasion, cake, muffins, scones and cake-type desserts contributed the greatest proportion of $\mathrm{Na}$ intake $(9.8 \%)$, followed by regular breads and bread rolls (6.9\%), mixed dishes where cereal is the major ingredient $(6 \cdot 8 \%)$, water $(5.7 \%)$ and cheese $(4.6 \%)$.

Table 2 Sodium intake from meals/snacks, according to age group, among a nationally representative sample of Australian adults aged 18-84 years with known height and weight ( $(7818)$, Australian Health Survey (2011-13)

\begin{tabular}{|c|c|c|c|c|c|c|c|c|c|}
\hline \multirow[b]{2}{*}{ Nutrient } & \multicolumn{2}{|c|}{$18-30$ years } & \multicolumn{2}{|c|}{$31-50$ years } & \multicolumn{2}{|c|}{$51-70$ years } & \multicolumn{2}{|c|}{$71-84$ years } & \multirow[b]{2}{*}{$P$ value } \\
\hline & Mean & SE & Mean & $\mathrm{SE}$ & Mean & $\mathrm{SE}$ & Mean & SE & \\
\hline $\mathrm{Na}$ intake during meal times (\% of total daily $\mathrm{Na}$ intake) & $78 \cdot 6$ & 0.7 & $80 \cdot 3$ & 0.5 & $81 \cdot 7$ & 0.6 & $85 \cdot 1$ & 0.8 & 0.001 \\
\hline $\mathrm{Na}$ intake during between-meal times (\% of total daily $\mathrm{Na}$ intake) & 21.4 & 0.7 & $19 \cdot 7$ & 0.5 & $18 \cdot 2$ & 0.6 & 14.9 & 0.8 & 0.001 \\
\hline
\end{tabular}




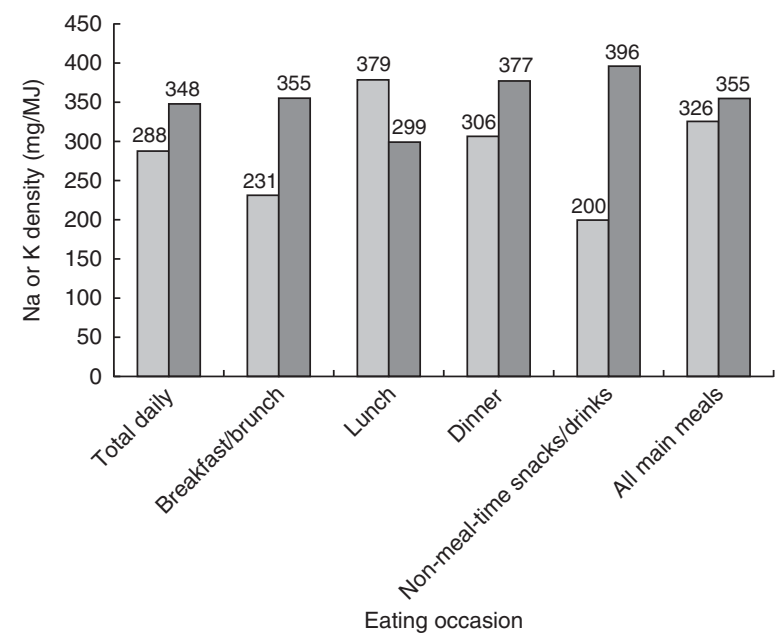

Fig. 3 Sodium density ( $\square$ ) and potassium density ( $\square$ ) of each meal/snack among a nationally representative sample of Australian adults aged 18-84 years with known height and weight ( $n$ 7818), Australian Health Survey (2011-13)

Top food sources of $\mathrm{K}$ intake also differed across various meal times. The top food group sources of $\mathrm{K}$ at each of the meal times were dairy milk (cow, sheep goat) at breakfast (108.1 mg; 20.5\%), mixed dishes where cereal is the major ingredient at lunch $(66.7 \mathrm{mg} ; 10.9 \%)$, potatoes at dinner (159.9 mg; $15.2 \%$ ), and coffee and coffee substitutes at between-meal eating occasions (107 mg; 13.9\%).

The other major food sources of $\mathrm{K}$ intake at breakfast were breakfast cereals $(74.2 \mathrm{mg} ; 14.1 \%)$, coffee and coffee substitutes $(37.1 \mathrm{mg} ; 7 \cdot 0 \%)$, and fruit and vegetable juices and drinks $(35.9 \mathrm{mg} ; 10.7 \%)$. At lunch, the major contributors were mixed dishes where cereal is the major ingredient (66.7 mg; $10.9 \%)$, potatoes $(46.8 \mathrm{mg} ; 7.6 \%)$, regular breads and bread rolls ( $44.3 \mathrm{mg} ; 7.2 \%$ ), dishes where vegetable is the major component $(33.1 \mathrm{mg} ; 5.4 \%)$ and poultry and feathered game $(28.4 \mathrm{mg} ; 4.6 \%)$, and beef, sheep, pork, unprocessed (27.9 mg; $4.6 \%)$. Potatoes contributed the greatest proportion of $\mathrm{K}$ at dinner (159.9 mg; 15.2\%), followed by mixed dishes where cereal is the major ingredient (111.9 mg; 10.7\%), beef, sheep, pork, unprocessed $(93.9 \mathrm{mg} ; 9.0 \%)$, mixed dishes where beef, sheep, pork or mammalian game is the major component (66.3 mg; $6.3 \%$ ), mixed dishes where poultry or feathered game is the major ingredient $(56.5 \mathrm{mg} ; 5.4 \%)$, and poultry and feathered game $(51.8 \mathrm{mg} ; 4.9 \%)$.

At the defined snack/between-meal time occasion, coffee and coffee substitutes contributed the greatest proportion of $\mathrm{K}$ intake $(107.0 \mathrm{mg} ; 13.9 \%$ of $\mathrm{K}$ at snack time), followed by regular dairy milk (cow, sheep and goat; $81.2 \mathrm{mg} ; 10.6 \%)$, beers (40.8 mg; $5.3 \%)$, tropical and subtropical fruit $(38.7 \mathrm{mg} ; 5.0 \%)$, and fruit and vegetable juice and drinks (38.0 mg; 5.0\%).

\section{Discussion}

The present paper has reported the major food group contributors to $\mathrm{Na}$ and $\mathrm{K}$ intakes in a nationally representative sample of Australian adults. The food sources of $\mathrm{Na}$ and $\mathrm{K}$ according to meal and between-meal eating occasions are also reported. It was shown that breads, cereals and mixed dishes were significant contributors to daily intakes of both nutrients, and that major food sources of $\mathrm{Na}$ and $\mathrm{K}$ differed between defined eating occasions.

Regular breads and bread rolls (plain/unfilled/untopped varieties) contributed the greatest proportion of $\mathrm{Na}$ intake in adults $(93.5 \mathrm{mg}$ ( $24.5 \%$ of total $\mathrm{Na}$ ) and $133.7 \mathrm{mg}$ (17.3\% of total $\mathrm{Na}$ ) at breakfast and lunch, respectively). This is consistent with other reports that bread contributes substantially to $\mathrm{Na}$ intake in Australian adults and in other developed countries ${ }^{(12)}$. As bread is already recognised for the significant contribution it makes to total $\mathrm{Na}$ intake, efforts have focused on reducing the $\mathrm{Na}$ content with over $50 \%$ of brands in 2012 containing $400 \mathrm{mg} \mathrm{Na}$ or less per $100 \mathrm{~g}$ in Australia and New Zealand ${ }^{(30)}$.

At the minor food group level for mixed dishes where cereal is the major ingredient (5-digit AUSNUT code), it is evident that the major contributors to daily $\mathrm{Na}$ are takeaway foods such as burgers, pizza and tacos, which contribute to the high proportion of this food group to total daily $\mathrm{Na}$ intake. A report previously published by the George Institute documented the range of $\mathrm{Na}$ content of commonly consumed takeaway foods ${ }^{(31)}$. It was reported that takeaway pizza is one of the foods with the highest $\mathrm{Na}$ content (three slices containing $2300 \mathrm{mg}$ ).

The major contributor to $\mathrm{K}$ intake was potatoes. However, cooking methods, which include frying and the addition of table salt, may compromise the nutritional quality of this food. Although fruits and vegetables are identified as good sources of $\mathrm{K}$, neither featured as a major contributor to $\mathrm{K}$ intake, other than potato. This reflects the inadequate consumption of these foods, which is supported by the high proportion of Australian adults who do not usually meet national recommendations for fruit (2 servings/d) and vegetables ( 5 servings $/ \mathrm{d})^{(16)}$.

The other major findings are that dinner contributes the greatest proportion of $\mathrm{Na}$ to total daily $\mathrm{Na}$ intake (31\%) but that $\mathrm{Na}$ density is highest at lunch $(379 \mathrm{mg} / \mathrm{MJ} v$. dinner $306 \mathrm{mg} / \mathrm{MJ}$ ), which is consistent with findings previously published in a sample of older Australian adults ${ }^{(12)}$. This reflects the differences in $\mathrm{Na}$ density of some of the main food group contributors to the different meal occasions. Lunch is characterised by consumption of dishes like filled sandwiches made with breads/rolls and typical fillings like cheeses and processed meats, spreads and sauces, which are all high-Na foods ${ }^{(32)}$. Data from the National Health and Nutrition Examination Survey 2009-10 showed that US adults who reported eating a sandwich on the day of the survey had significantly higher energy and $\mathrm{Na}$ intakes compared with individuals who did not eat a sandwich ${ }^{(32)}$. The frequent consumption of sandwiches with these typical ingredients and considerable contributions to $\mathrm{Na}$ intake means that substituting the higher-Na ingredients 
with low-Na higher-K ingredients (like vegetables) in sandwiches could significantly reduce $\mathrm{Na}$ intakes.

In contrast to $\mathrm{Na}$ density, $\mathrm{K}$ density was lowest at lunch and highest for between-meal eating occasions (299 $v$. $396 \mathrm{mg} / \mathrm{MJ})$. This likely reflects coffee consumption incorporating milk at mid-meals whereas lunch typically comprised mixed dishes/cereals. This finding may also indicate low fruit and vegetable consumption at lunchtime, and consequently this presents an opportunity for meal-based advice to improve food choices and nutritional quality of foods consumed at lunches.

Between-meal time $\mathrm{Na}$ intake contributed approximately one-fifth (19\%) of total daily $\mathrm{Na}$ intake, which is substantially higher than the $11 \%$ that has been reported previously in Australian adults ${ }^{(12)}$. We found that the foods that contributed the greatest proportion of $\mathrm{Na}$ intake at between-meal eating occasions were cakes, muffins, scones and cake-type desserts, contributing $9.8 \%$ of total $\mathrm{Na}$ intake between meals. Bakery products often use $\mathrm{Na}$ to enhance flavour in addition to use of other Na-containing additives such as sodium citrate and raising agents such as sodium bicarbonate ${ }^{(33)}$. A recent Food Standards Australia New Zealand report that sampled the $\mathrm{Na}$ content of a range of bakery products found they ranged from an average of $229 \mathrm{mg} / 100 \mathrm{~g}$ for sweet biscuits to $805 \mathrm{mg} / 100 \mathrm{~g}$ for savoury biscuits ${ }^{(34)}$. A recent report documenting progress with the Australian Food and Health Dialogue identified bakery products as a reformulation target ${ }^{(35)}$. That report highlighted inaction setting or reaching proposed $\mathrm{Na}$ reduction targets for breads, cereals, sauces, processed meats and snack foods ${ }^{(35)}$. This highlights the important need for public policy to create a food supply that supports healthier choices and for the food industry to cooperate with this endeavour.

In the present study, the top food contributors to $\mathrm{Na}$ intake varied by quintile of $\mathrm{Na}$ consumption. Breads and mixed dishes were the highest contributors to $\mathrm{Na}$ intake in both the lowest and highest quintiles of $\mathrm{Na}$ intake, which likely reflects that these are staple foods in many Australian diets. Among consumers in the highest quintile of $\mathrm{Na}$ intake, the major sources of $\mathrm{Na}$ were highly processed foods: processed meats, sausages and pastries. Processed foods may also contain higher amounts of saturated fat and sugar than less processed foods ${ }^{(36)}$. Among those in the lowest quintile of $\mathrm{Na}$ consumption, the top food sources of $\mathrm{Na}$ were less processed foods. The highest consumers of $\mathrm{Na}$ were consuming more $\mathrm{Na} / \mathrm{MJ}$ than the lowest quintile of consumers. This may reflect that these high $\mathrm{Na}$ consumers are eating more overall, but indicates their diets are of poorer quality than those consuming lowest amounts of $\mathrm{Na}$ who are closest to meeting targets for $\mathrm{Na}$ intake to prevent chronic disease.

Another key observation was that younger adults consume a greater proportion of their $\mathrm{Na}$ intake at snack times compared with older adults. This is consistent with reports documenting school-aged children consume a greater proportion of $\mathrm{Na}$ from snacks compared with meals ${ }^{(23,24)}$. This likely reflects the diet patterns of younger adults: their greater tendency to graze between defined meal occasions during the day/night compared with older people, who tend to consume foods at defined main meal eating occasions ${ }^{(37)}$.

Advice to reduce $\mathrm{Na}$ and increase $\mathrm{K}$ intake may benefit from approaches based on meal times. Current food-based dietary guidelines (Australian Dietary Guidelines) specify 'Limit intake of foods and drinks containing added salt'(16). This is inherently difficult for individuals because $\mathrm{Na}$ is a commonly used food additive; it is estimated that $75-85 \%$ of dietary $\mathrm{Na}$ comes from processed foods ${ }^{(38)}$. Strategies to support dietary guidelines include: 'Read labels to choose lower sodium options among similar foods' and 'Do not add salt to foods in cooking or at the table ${ }^{,(16)}$. Foods that contributed most to $\mathrm{Na}$ may not be recognisable to the consumer as high-Na foods, such as bread, cakes, biscuits and pastries. Moreover, these foods do not typically have low-salt or reduced-salt alternatives readily available. Encouraging individuals to read labels to identify lower-Na products may not adequately support an individual to lower $\mathrm{Na}$ intake either, with a recent Food Standards Australia New Zealand report finding that 15\% of 363 packaged and takeaway foods in Australia had Na content $\geq 20 \%$ above the $\mathrm{Na}$ content specified on the label, reflecting inaccuracy of information available ${ }^{(34)}$.

\section{Limitations}

In determining the average $\mathrm{Na}$ content of Australian food products, calculations were based on the foods that the participants had eaten on the day of the survey and nutrient values were obtained from the nutrient composition database AUSNUT 2011-13 ${ }^{(27)}$. No laboratory analyses were conducted to determine Na values of food products and reported Na content was used. The AUSNUT 2011-13 set of files reflects the food supply at the time period and may not accurately reflect the nutrient composition of foods if manufacturers have in this period of time modified the Na content of some foods ${ }^{(20)}$. The results may also not be generalisable to other countries with different $\mathrm{Na}$ and $\mathrm{K}$ content of the food supply or different eating habits. As the data described are based on one $24 \mathrm{~h}$ recall, this does not necessarily represent the respondent's usual dietary intake or eating pattern.

The current study did not include estimates of discretionary $\mathrm{Na}$ ( $\mathrm{Na}$ from salt added at the table or in cooking) or of $\mathrm{Na}$ from dietary supplements or medications, so total daily $\mathrm{Na}$ intake reported in the current study is likely to be an underestimate of total $\mathrm{Na}$ intake given that $64 \%$ of adults in Australia report adding salt to foods during preparation or at the table.

We also recognise the limitations inherent in the $24 \mathrm{~h}$ diet recall method for estimating dietary $\mathrm{Na}$ intake. The gold standard for estimating dietary $\mathrm{Na}$ intake is using $24 \mathrm{~h}$ urinary $\mathrm{Na}$ excretion. Estimates presented here based on the $24 \mathrm{~h}$ recall data are likely to be an underestimate of 
total daily $\mathrm{Na}$ intake, as we have not been able to account for the amount of discretionary $\mathrm{Na}$ added to foods and do not have urinary $\mathrm{Na}$ excretion data available. In a recent study, Santos et al. used indirect methods to estimate total daily salt intake among the population in Australia and reported this intake as $9.0-9.9 \mathrm{~g} / \mathrm{d}$. This is a much higher estimate than the $6.2 \mathrm{~g}$ salt/d reported from dietary intake alone from the AHS 2011-12 $2^{(11)}$. A recent cross-sectional study of urinary compared with dietary recall methods to estimate $\mathrm{Na}$ intake in a US sample reported low correlation and substantial differences between $24 \mathrm{~h}$ diet recall and $24 \mathrm{~h}$ urinary $\mathrm{Na}$ excretion. It was reported that dietary estimates of $\mathrm{Na}$ intake were greater than the values estimated by urinary excretion, with the discrepancy (dietary $\mathrm{Na}$ - urinary $\mathrm{Na})$ being greater among men $(936.8 \mathrm{mg} / \mathrm{d})$ than women $(108.3 \mathrm{mg} / \mathrm{d})$ due to measurement error associated with both measurements ${ }^{(39)}$. Misreporting can also occur by $\mathrm{BMI}^{(26,40)}$. We also used self-reports of eating occasion in the current study to define meal time and between-meal time eating occasions. The accuracy of these self-reported eating patterns is uncertain ${ }^{(41)}$.

\section{Implications of findings}

This information sheds light on the contribution of foods including cakes, biscuits and pastries to $\mathrm{Na}$ intakes in Australian adults. It can inform food manufacturers, dietitians/nutritionists and consumers about the importance of improving food choices between meals in order to reduce $\mathrm{Na}$ intake and increase $\mathrm{K}$ intake.

\section{Conclusion}

The present study identified the major food sources of $\mathrm{Na}$ and $\mathrm{K}$ consumed by Australian adults at meal time and between-meal time eating occasions. The identification of these foods and their intake in the meal time/betweenmeal time context is important to inform population and individual consumer strategies to reduce $\mathrm{Na}$ intake ${ }^{(42)}$. These findings can contribute to meal-based approaches to complement current dietary guidelines regarding reducing dietary $\mathrm{Na}$ intake and increasing dietary $\mathrm{K}$ intake.

\section{Acknowledgements}

The data sets analysed during the current study are accessible on request to the Australian Bureau of Statistics (http://www.abs.gov.au/australianhealthsurvey). Financial support: This research received no specific grant from any funding agency in the public, commercial or not-for-profit sectors. Conflict of interest: The authors declare that they have no competing interests. Authorship: K.M.D., L.C. and C.J.M. designed the study, interpreted the results and wrote the manuscript. L.C. performed the statistical analyses. All other authors critically revised the manuscript for important intellectual content and approved the final manuscript.
Ethics of buman subject participation: The Census and Statistics Act 1905 provides ethics approval for the Australian Bureau of Statistics to conduct the household interview components of health surveys.

\section{Supplementary material}

To view supplementary material for this article, please visit https://doi.org/10.1017/S1368980017002968

\section{References}

1. O'Donnell M, Mente A, Rangarajan S et al. (2014) Urinary sodium and potassium excretion, mortality, and cardiovascular events. $N$ Engl J Med 371, 612-623.

2. Mente A, O'Donnell MJ, Rangarajan S et al. (2014) Association of urinary sodium and potassium excretion with blood pressure. $N$ Engl J Med 371, 601-611.

3. He FJ \& MacGregor GA (2009) A comprehensive review on salt and health and current experience of worldwide salt reduction programmes. J Hum Hypertens 23, 363-384.

4. Whelton PK, He J, Cutler JA et al. (1997) Effects of oral potassium on blood pressure. Meta-analysis of randomized controlled clinical trials. JAMA 277, 1624-1632.

5. Geleijnse JM, Kok FJ \& Grobbee DE (2003) Blood pressure response to changes in sodium and potassium intake: a metaregression analysis of randomised trials. J Hum Hypertens 17, $471-480$.

6. Binia A, Jaeger J, Hu Y et al. (2015) Daily potassium intake and sodium-to-potassium ratio in the reduction of blood pressure: a meta-analysis of randomized controlled trials. J Hypertens 33, 1509-1520.

7. Perez V \& Chang ET (2014) Sodium-to-potassium ratio and blood pressure, hypertension, and related factors. Adv Nutr 5, 712-741.

8. Yang QH, Liu TB, Kuklina EV et al. (2011) Sodium and potassium intake and mortality among US adults prospective data from the Third National Health and Nutrition Examination Survey. Arch Intern Med 171, 1183-1191.

9. National Health and Medical Research Council (2006) Nutrient Reference Values for Australia and New Zealand Including Recommended Dietary Intakes. Version 1.2, Updated September 2017. https://www.nhmrc.gov.au/_files_nhmrc/ file/your_health/healthy/nutrition/17599_nhmrc_nrv_updatedietary_intakes_0.pdf (accessed October 2017).

10. Australian Bureau of Statistics (2015) Australian Health Survey: Usual Nutrient Intakes 2011-12. http://www.abs. gov.au/ausstats/abs@.nsf/Lookup/4364.0.55.008main+features 12011-12 (accessed September 2015).

11. Santos JA, Webster J, Land MA et al. (2017) Dietary salt intake in the Australian population. Public Health Nutr 20, $1887-1894$.

12. Margerison C, Riddell LJ, Wattanapenpaiboon $\mathrm{N}$ et al. (2013) Dietary sources and meal distribution of sodium and potassium in a sample of Australian adults. Nutr Diet 70, 294-299.

13. Villani AM, Clifton PM \& Keogh JB (2012) Sodium intake and excretion in individuals with type 2 diabetes mellitus: a cross-sectional analysis of overweight and obese males and females in Australia. J Hum Nutr Diet 25, 129-139.

14. Charlton K, Yeatman H, Houweling F et al. (2010) Urinary sodium excretion, dietary sources of sodium intake and knowledge and practices around salt use in a group of healthy Australian women. Aust $N Z J$ Public Health 34, 356-363.

15. Food Standards Australia New Zealand (2008) Proposal P230 - Iodine Fortification - Dietary Intake Assessment Report. http://www.foodstandards.gov.au/code/proposals/pages/ proposalp230iodinefo2802.aspx (accessed September 2015). 
16. National Health and Medical Research Council (2013) Australian Dietary Guidelines. Canberra: NHMRC.

17. Fabry P, Fodor J, Hejl Z et al. (1968) Meal frequency and ischaemic heart-disease. Lancet 2, 190-191.

18. Wirfalt E, Hedblad B, Gullberg B et al. (2001) Food patterns and components of the metabolic syndrome in men and women: a cross-sectional study within the Malmo Diet and Cancer cohort. Am J Epidemiol 154, 1150-1159.

19. Dickinson KM, Clifton PM \& Keogh JB (2011) Endothelial function is impaired after a high-salt meal in healthy subjects. Am J Clin Nutr 93, 500-505.

20. Dickinson KM, Clifton PM, Burrell LM et al. (2014) Postprandial effects of a high salt meal on serum sodium, arterial stiffness, markers of nitric oxide production and markers of endothelial function. Atherosclerosis 232, 211-216.

21. Blanch N, Clifton PM \& Keogh JB (2014) Postprandial effects of potassium supplementation on vascular function and blood pressure: a randomised cross-over study. Nutr Metab Cardiovasc Dis 24, 148-154.

22. Blanch N, Clifton PM, Petersen KS et al. (2015) Effect of sodium and potassium supplementation on vascular and endothelial function: a randomized controlled trial. $\mathrm{Am} \mathrm{J}$ Clin Nutr 101, 939-946.

23. Macdiarmid J, Loe J, Craig LCA et al. (2009) Meal and snacking patterns of school-aged children in Scotland. Eur J Clin Nutr 63, 1297-1304.

24. Kerr MA, Mccrorie TA, Rennie KL et al. (2010) Snacking patterns according to location among Northern Ireland children. Int J Pediatr Obes 5, 243-249.

25. Australian Bureau of Statistics (2013) Australian Health Survey: Users' Guide, 2011-13. http://www.abs.gov.au/ AUSSTATS/abs@.nsf/Lookup/4363.0.55.001Main+Features 12011-13?OpenDocument (accessed September 2015).

26. Moshfegh AJ, Rhodes DG, Baer DJ et al. (2008) The US Department of Agriculture Automated Multiple-Pass Method reduces bias in the collection of energy intakes. Am J Clin Nutr 88, 324-332.

27. Food Standards Australia New Zealand (2015) AUSNUT 2011-13 Food Nutrient Database. http://www.foodstandards. gov.au/science/monitoringnutrients/ausnut/foodnutrient/ Pages/default.aspx (accessed September 2015).

28. Food Standards Australia New Zealand (2015) Australian Food, Supplement and Nutrient Database (AUSNUT): Uncertainty and limitations. http://www.foodstandards.gov. $\mathrm{au} /$ science/monitoringnutrients/ausnut/foodnutrient/Pages/ uncertainty.aspx\# (accessed August 2017).

29. Krebs-Smith SM, Kott PS \& Guenther PM (1989) Mean proportion and population proportion: two answers to the same question? J Am Diet Assoc 89, 671-676.
30. Dunford EK, Eyles H, Mhurchu CN et al. (2011) Changes in the sodium content of bread in Australia and New Zealand between 2007 and 2010: implications for policy. Med J Aust 195, 346-349.

31. Garcia J, Dunford EK, Sundstrom J et al. (2014) Changes in the sodium content of leading Australian fast-food products between 2009 and 2012. Med J Aust 200, 340-344.

32. Sebastian RS, Wilkinson Enns C, Goldman JD et al. (2015) Sandwiches are major contributors of sodium in the diets of American adults: results from What We Eat in America, National Health and Nutrition Examination Survey 2009-2010. J Acad Nutr Diet 115, 272-277.

33. Yee KK, Sukumaran SK, Kotha R et al. (2011) Glucose transporters and ATP-gated $\mathrm{K}^{+}$(KATP) metabolic sensors are present in type 1 taste receptor 3 (T1r3)-expressing taste cells. Proc Natl Acad Sci US A 108, 5431-5436.

34. Food Standards Australia New Zealand (2015) Sodium levels in a range of packaged and take-away foods. http:// www.foodstandards.gov.au/publications/pages/sodiumlevels inarange4648.aspx (accessed September 2015).

35. Elliott T, Trevena H, Sacks G et al. (2014) A systematic interim assessment of the Australian Government's Food and Health Dialogue. Med J Aust 200, 92-95.

36. Poti JM, Mendez MA, Ng SW et al. (2015) Is the degree of food processing and convenience linked with the nutritional quality of foods purchased by US households? Am J Clin Nutr 101, 1251-1262.

37. Holmback I, Ericson U, Gullberg B et al. (2010) Five meal patterns are differently associated with nutrient intakes, lifestyle factors and energy misreporting in a sub-sample of the Malmo Diet and Cancer cohort. Food Nutr Res 2009, 53

38. Webster JL, Dunford EK \& Neal BC (2010) A systematic survey of the sodium contents of processed foods. Am JClin Nutr 91, 413-420.

39. Mercado CI, Cogswell ME, Valderrama AL et al. (2015) Difference between 24-h diet recall and urine excretion for assessing population sodium and potassium intake in adults aged 18-39 y. Am J Clin Nutr 101, 376-386.

40. Espeland MA, Kumanyika S, Wilson AC et al. (2001) Statistical issues in analyzing 24-hour dietary recall and 24-hour urine collection data for sodium and potassium intakes. Am J Epidemiol 153, 996-1006.

41. Leech RM, Worsley A, Timperio A et al. (2017) Temporal eating patterns: a latent class analysis approach. Int J Behav Nutr Phys Act 14, 3.

42. Leech RM, Worsley A, Timperio A et al. (2015) Understanding meal patterns: definitions, methodology and impact on nutrient intake and diet quality. Nutr Res Rev 28, 1-21. 